\title{
INTERPRETACJA STANOWISK PRAHISTORYCZNYCH NIAUX I LA VACHE W PIRENEJACH JAKO „MIEJSC PAMIĘCI” I „KRAJOBRAZU PAMIECI”
}

\author{
THE INTERPRETATION OF THE PREHISTORIC SITES NIAUX \\ AND LA VACHE AS "SITES OF MEMORY" \\ AND "LANDSCAPE OF MEMORY"
}

\author{
Anna Głód \\ Instytut Archeologii i Etnologii PAN, Ośrodek Studiów Pradziejowych i Średniowiecznych \\ ul. Rubież 46, 61-612 Poznań, Poland \\ anna_glod-90@wp.pl
}

\begin{abstract}
This article is an attempt to interpret Niaux prehistoric sites (where rites and rock paintings were discovered) and La Vache (the place where the prehistoric people were camped) in the Pyrenees as "sites of memory" and "landscape of memory". The article attempts to answer the question of whether cave positions that are the subject of the work can be interpreted and defined as "sites of memory" from a modern point of view, and whether the cave in Niaux could be a kind of "site of memory" for the prehistoric population. Additionally, whether the area within which these two caves are located can be considered as part of the "landscape of memory".
\end{abstract}

KEY WORDS: Paleolithic art, "sites of memory", "landscape of memory"

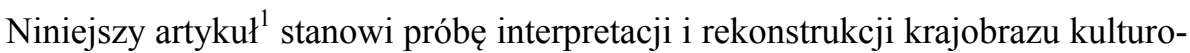
wego społeczności łowiecko-zbierackiej kultury magdaleńskiej, użytkującej niegdyś dwie jaskinie: Niaux i La Vache (departament Ariège, dolina Vicdessos). Postaram się odpowiedzieć na pytanie, czy można rozpatrywać go w ramach „krajobrazu pa-

\footnotetext{
${ }^{1}$ Artykuł stanowi wyciąg z pracy magisterskiej zatytułowanej „,Miejsca pamięci” $w$,,krajobrazie pamięci”. Próba interpretacji i rekonstrukcji krajobrazu kulturowego społeczności zbieracko-łowieckiej kultury magdaleńskiej - stan Niaux, region Oksytania, departament Ariège napisanej pod kierownictwem prof. zw. dr hab. Danuty Minty-Tworzowskiej.
} 
mięci". Dodatkowo, czy będące przedmiotem pracy stanowiska jaskiniowe można ze współczesnego punktu widzenia interpretować i definiować jako „miejsca pamięci” oraz czy jaskinia w Niaux mogła stanowić swoiste „miejsce pamięci” już dla ludności pradziejowej.

Przestrzenny wymiar rejestrowanych przez archeologa zjawisk od dawna cieszył się i cieszy szerokim zainteresowaniem. Genezy zainteresowania przestrzenią w archeologii należy szukać na początku XX wieku, kiedy została wydzielona pierwsza jednostka związana z tą kategorią - prowincja kulturowa. Koncepcja ta wyparła ewolucjonistyczne podejście w myśleniu o przeszłości. Kultury archeologiczne analizowano $\mathrm{w}$ aspekcie historycznym i ,to w tych jednostkach klasyfikacyjnych badacze widzieli formy państwowe, narodowe lub [...] rasowe" (Banaszek, 2015, s. 17). Wtedy to przestrzeń postrzegano jako obiektywne, bierne tło. Sytuacja ta ulega zmianie, kiedy archeolodzy zwrócili uwagę na perspektywę fenomenologiczną $i$ hermeneutyczną. Grupa badaczy nazywanych archeologami humanistycznymi lub konstruktywistycznymi (Trigger, 2007, s. 427; Banaszek, 2015, s. 25) zajęła się problemem ludzkiego zaangażowania $\mathrm{w}$ krajobrazie, jego postrzeganiem przez przeszłe społeczności oraz współczesnym jego odbiorem. Archeolodzy konstruktywistyczni nie patrzyli na przestrzeń jak na bierne tło ludzkiego działania, a krajobraz jawi się $w$ ich ujęciu jako dynamiczny, nieskończony, wieloznaczny, zmienny (Woźny, 2000, s. 36; Marciniak, 2012, s. 87-91; Banaszek, 2015, s. 26-27; Polkowski, 2016, s. 90-92).

Co istotne, krajobraz w ujęciu fenomenologicznym traktowany jest jako kategoria dynamiczna i subiektywna, tak też postrzegany jest współcześnie.

W poszukiwaniu naukowych sposobów interpretacji krajobrazu przeszłego, prób jego odczytywania, jak widać, doszło do istotnej zmiany w relacji przedmiot - podmiot badań; [są one - przyp. A.G.] całkowicie powiązane [...] gdyż przedmiot badań jako wartość kulturowa powstaje w wyniku tarcia zachodzącego w relacjach społecznych funkcjonujących w danym kontekście. Jej czyste znaczenie nie istnieje ani w obliczu hermeneutycznego przedrozumienia, ani emocji, jakie wywołuje ona w umyśle badacza; umyśle osadzonym w indywidualnym ciele. (Banaszek, 2015, s. 27)

Obecnie kategoria krajobrazu cieszy się sporym zainteresowaniem badawczym wśród różnych dyscyplin naukowych. Koncepcja „miejsc pamięci” także wpisuje się w ów nurt. We współczesnej humanistyce „miejsca pamięci” stały się popularnym przedmiotem badań o wymiarze międzynarodowym. Ta swoista „moda” nie ominęła także archeologii, na gruncie której zagadnienie „miejsc pamięci” stało się tematem licznych publikacji i konferencji naukowych (Szpociński, 2008, s. 11; Zalewska, 2015, s. 61-63, tam dalsza literatura).

W ujęciu fenomenologicznym „miejsca” były jedną ze składowych krajobrazu. Przez miejsce można go było doświadczyć (Ingold, 1993; Tilley, 1994). Ch. Tilley postrzega je jako odzwierciedlenie ludzkiej aktywności, wyznawanych wartości, 
ponieważ stanowią obraz zaangażowania w świat. Jednak tak postrzegane miejsce może utracić swoje znaczenie, a istotny jest tu czas, który stanowi konieczny elementem w ludzkim doświadczeniu miejsca, ponieważ owo doświadczenie ,musi być powiązane z wymianą, przepływem lub kontynuacją” (Frydryczak, 2015, s. 116). Tym, co łączy ludzi z miejscem, mogą być mity, rytuały, wartości. Kiedy jego aspekt czasowy nie jest już uchwytny dla jakiejś społeczności, staje się ono „martwe" - traci znaczenie (Tilley, 1994, s. 15, 32-33; Frydryczak, 2015, s. 116).

Pamięć, przestrzeń i tożsamość stanowią kategorie, które od najdawniejszych czasów charakteryzuje silny, wręcz nierozerwalny wzajemny związek. Wraz z początkiem lat 70. XX wieku we francuskiej myśli naukowej można dostrzec zmianę w podejściu do pojęcia pamięci. Istotny wpływ na kierunek owych przemian wywarły prace francuskiego historyka Pirre'a Nory. Badacz ten nawiązywał w swoich rozważaniach do idei ram pamięci zbiorowej autorstwa Maurica Halbwachsa (2008) oraz badał zjawisko starożytnej i średniowiecznej retoryki. To on widział potrzebę studiów nad tak zwanymi „miejscami pamięci” (Minta-Tworzowska, 2015a, s. 13-16). P. Nora stwierdził, że zainteresowania kategorią pamięci należy łączyć z obszarem Europy. Za ich początek uznaje okres po II wojnie światowej, ale niejako „rozkwit” nastąpił w latach 80. XX wieku i w publikacjach naukowych często określany jest mianem „rewolty pamięci”. Przyczyną narodzin owych zainteresowań jest zdaniem tego badacza rozpad społeczności tradycyjnych oraz proces unowocześniania świata. Skutkiem tych mechanizmów była utrata wcześniejszych przekazów pamięci historycznej, przez co zrodziła się potrzeba nowego i ponownego upamiętniania owych przestrzeni. Wynikiem tych procesów były nowo powstałe, jak i niekiedy na nowo odkryte „miejsca pamięci” (Nora, 2001, s. 37-43; Minta-Tworzowska, 2015a, s. 13).

Pojęcie pamięci, tak jak i wiele innych pojęć, zostało ,historycznie ukształtowane”. Współcześnie można dostrzec kilka głównych ujęć tej kategorii. Istotne wydają się dwa stanowiska. Pierwsze z nich zakłada, że pamięć ma charakter jednoznaczny, czyli że stanowi twór zdeterminowany przez przeszłość. Drugie podejście antycypuje sytuację odwrotną, że to teraźniejszość określa pamięć. Zakłada, że w danej społeczności pamięta się to, co w określonej sytuacji dziejowej, politycznej jest dla niej istotne. „Żadna pamięć nie jest w stanie zachować przeszłości jako takiej. Pozostaje z niej tylko to, co społeczność w każdej epoce jest w stanie zrekonstruować za pomocą aktualnych ram odniesienia" (Assmann, 2003, s. 14-15). Wspomnienia podlegają selekcji, ale i przekształceniom zależnie od obecnych standardów kulturowych. Tak więc pamięć zbiorowa ma charakter społeczny, jest kreowana z punktu widzenia teraźniejszości i jest w niej zakotwiczona (Assmann, 2003, s. 14-15; Minta-Tworzowska, 2015a, s. 13, 14; Żuk, 2015, s. 93).

„Przeszłość jednak [jak uważa Jan Assmann na łamach pracy Pamięć kulturowa (2008, s. 47) - przyp. A.G.] powstaje dopiero dzięki temu, iż jest przedmiotem odniesienia. Jej znaczenie może być użytkowe (dyskurs władzy) lub symboliczne. To przeszłość jest społecznie zapamiętana/zapamiętywana” (Minta-Tworzowska, 2015a, 
s. 13-14). J. Assmann wydziela trzy formy pamięci: pamięć jednostkową, komunikatywną oraz kulturową. Pamięć jednostkowa wiąże się z indywidualnym doświadczeniem, pamięć komunikatywna kształtuje się przez przekazy ustne, ale w związku $\mathrm{z}$ tym jest ograniczona czasowo - trwa do stu lat. Pamięć kulturowa natomiast kształtuje się po okresie „strefy milczenia” w sytuacji, gdy nie ma już „strażników pamięci”, czyli ostatniego pokolenia realnie z nią związanego. Sytuacja taka niejako wymusza utrwalenie tej pamięci poza sferą indywidualną, przez tworzenie jej „obrazów" w materialnych formach, np. pomnikach, budowlach czy rytuałach. A z kolei takie połączenie pamięci społecznej o przeszłości z realnie istniejącymi w teraźniejszości np. pomnikami, praktykami ceremonialnymi itp. sprawia, że dalej spełnia ona swoją funkcję. Dodatkowo każda pamięć kulturowa ma „punkty stałe”, którymi mogą być istotne dla danej społeczności pojedyncze wydarzenia upamiętniane w różny sposób. Badacz określa je mianem „figur wspomnień”, a pamięć kulturowa się na nich opiera (Assmann, 2001, za: Minta-Tworzowska, 2015a, s. 15).

W nieco późniejszej pracy J. Assmann definiuje pamięć kulturową jako „pojęcie obejmujące wszelką wiedzę, która w specyficznych ramach interakcji zachodzących w danej społeczności kieruje jej działaniem i przeżyciami oraz w której ćwiczą się i w którą są wprowadzeni jej członkowie z pokolenia na pokolenie" (Assmann, 2003, s. 11).

Prowadząc badania dotyczące tak odległego okresu, jakim są pradzieje, pojawia się istotny problem, a mianowicie wydaje się rzeczą oczywistą, że współczesne podejście, rozumienie, a może też percepcja przestrzeni i czasu są odmienne od ich postrzegania w społecznościach pradziejowych. Problem ten, jak i próba rekonstrukcji percepcji przestrzeni i czasu w owych społecznościach wielokrotnie były przedmiotem badań uczonych reprezentujących różne dyscypliny naukowe. Warto pokrótce wskazać najważniejsze dla moich rozważań wymieniane przez badaczy cechy sposobu postrzegania przestrzeni i czasu, które odnieść można do społeczności łowiecko-zbierackiej kultury magdaleńskiej.

Mimo że kategoria łowców-zbieraczy jest bardzo ogólna i odnieść ją można do wielu ludów reprezentujących odmienne kultury, to w pracy tej przyjęto za T. Płonką, że ogólne zasady ich podstaw gospodarczych, życia społecznego, stosowanych technologii są bardzo podobne (Płonka, 2012, s. 47). Społeczności paleolitycznych kultur, jak stwierdza wielu badaczy, cechowało tak zwane „myślenie magiczne”, którego główną cechą jest synkretyzm sfer światopoglądowej, utylitarnej i komunikacyjnej - sfery sacrum i profanum także nie są wydzielane, ponieważ każda czynność nacechowana była magicznie (Kowalski, 1999, s. 15; Kuczyńska, 2011, s. 51-52; Płonka, 2012, s. 149). Taka postawa ma istotny wpływ na percepcję czasu i przestrzeni. Działanie członków tych grup cechuje cykliczność, stałe powtarzanie przyjętego wzorca postępowania, który, jak podają wyniki badań etnograficznych, mógł być uznawany za działanie mitycznego przodka, czyli coś, co zostało ustanowione „u początku”. Tak więc to, co w naszym ujęciu przeszłe i teraźniejsze wśród tych 
społeczności jest ściśle powiązane i stanowi, odnosi się do, jak stwierdził P. Nora, tego, co „teraz” (Nora, 1974, s. 401, za: Minta-Tworzowska, 2015a, s. 16).

Percepcja przestrzeni wśród społeczności łowiecko-zbierackich ma charakter decentralistyczny, jak uznał $\mathrm{Ch}$. Tilley, i cechuje ją funkcjonowanie wielu znaczących miejsc. Podział przestrzeni/krajobrazu prawdopodobnie opierał się na widocznych, wyróżniających się elementach fizycznych, którym przypisywano znaczenia symboliczne. Badania etnograficzne dowodzą, że wiele ludów tego typu uznaje, że ziemia powstała w wyniku działania np. mitycznego przodka/przodków i specyficzne elementy topograficzne ukształtowały się za ich sprawą albo że stanowią właśnie owych przodków niejako „wtopionych” w krajobraz (Tilley, 1994, s. 36, 38-39). Istotnym elementem przestrzeni były zapewne obozowiska. T. Płonka stwierdził, że założenia te $\mathrm{w}$ ramach kultury magdaleńskiej miały zapewne granice wytyczane symbolicznie, a sama przestrzeń wewnątrz nich była organizowana na podstawie funkcjonującego schematu (Płonka, 2012, s. 412). Innym wyróżniającym się typem stanowiska archeologicznego odnoszącego się do tej kultury były jaskinie z rytami i malowidłami naskalnymi. W ramach organizacji przestrzeni w ich wnętrzu można wskazać pewne elementy stałe. Ryty i malowidła były często lokalizowane w głębokich partiach tych założeń, gdzie nie sięgało światło naturalne. Fakt ten miał zapewne istotny wpływ na postrzeganie owej przestrzeni. Dostrzec można także, że często wykorzystywano naturalną fakturę lub barwę skały, które przypominać mogły np. część figury zwierzęcej. Chociaż aktualnie nie mamy narzędzi do „odczytania” znaczeń owych struktur, a wiele prób ich odkrycia jest współcześnie krytykowanych, należy przyjąć, że przestrzeń tych jaskiń cechuje się przemyślanym układem rozmieszczenia malowideł i rytów (Leroi-Gourhan, 1966, s. 72-87; Kordys, 1991, s. 99; Płonka, 2012, s. 71-72; Minta-Tworzowska, 2015b, s. 346).

Początki badań nad „miejscami pamięci” zwykle łączy się z osobą Pirre'a Nory (Szpociński, 2008, s. 11). Ten francuski historyk w swoich pracach wyróżnił „,rzeczywistość pamięci” i „miejsca pamięci” (Nora, 1996b, za: Żuk, 2015, s. 79-81). Stwierdził, że

jeśli wyrażenie lieu de memoire musi posiadać jakąś oficjalną definicję, to będzie ona następująca: lieu de memoire to każdy istotny byt, zarówno materialny, jak i niematerialny w swej naturze, który wysiłkiem ludzkiej woli lub poprzez pracę czasu stał się symbolicznym elementem dziedzictwa pamięci danej społeczności. (Nora 1996a, s. XVII, za: Żuk, 2015, s. 79-81)

A w pracy z 2001 r. scharakteryzował je jako:

miejsca, w dokładnym znaczeniu tego słowa, gdzie pewne wspólnoty - jakie by one nie były - naród, rodzina, grupa etniczna, partia przechowująca swoje pamiątki (souvenirs) lub uznają ją za niezbywalną część swojej osobowości: miejsca topograficzne, jak na przykład archiwa, biblioteka czy muzea; miejsca monumenty - pomniki, cmentarze, architektura; miejsca symboliczne, takie jak rocznice, pielgrzymki, upamiętnienia; miejsca 
funkcjonalne - stowarzyszenia, autobiografie, podręczniki. (Nora, 2001, za: Minta-Tworzowska, 2015a, s. 17)

Pierwotnie kategoria „miejsc pamięci” odwoływała się do materialnych aspektów przestrzeni. $\mathrm{W}$ archeologii początkowo w taki sposób interpretowano obiekty, które zaznaczały się w krajobrazie swoją monumentalną formą. P. Nora uznał, że „pewne ważne stanowiska pradziejowe, geograficzne i archeologiczne muszą być potraktowane jako lieux de memoire, mimo braku jakiejkolwiek intencji ich pamiętania, ponieważ brak ten jest rekompensowany pracą czasu i nauki oraz ludzkimi marzeniami i pamięcią, które stanowią przytłaczający argument za ich włączeniem" (Nora, 1996b, s. 16). Badacz wymienił zasady, które muszą być spełnione, aby dane miejsce mogło uchodzić za „miejsce pamięci”. Po pierwsze cechą takiej przestrzeni musi być „wola pamiętania” go. Następną zasadą jest upływ czasu oraz „zdolność do przemiany, potencjał do kreowania nowych znaczeń i treści w zmieniających się warunkach społecznych”, ponieważ miejsca te „mają za zadanie «zatrzymać czas〉, a jednocześnie dostosować się do zmiennych warunków społecznych" (Nora, 1996b, s. 15). Dodatkowo stwierdził, że aby zaistniały „miejsca pamięci”, konieczne jest zerwanie z „rzeczywistością pamięci”. Natomiast, jak zauważył, w ramach społeczności pradziejowych pamięć o przeszłości jest stale obecna w codziennym doświadczeniu. W nich to zostaje ona urealniona przez tradycję, rytuał. Nie ma tam podziału na teraźniejsze i przeszłe, ponieważ w takim ujęciu funkcjonują one jednocześnie. Tak więc, jego zdaniem, w czasach przedhistorycznych nie można mówić o kategorii „miejsc pamięci” (Nora, 1996b, s. 15, 16, za: Żuk, 2015, s. 79-84). Odmienny pogląd zaprezentował C. Holtorf oraz Lidia Żuk, zostanie on omówiony w dalszej części artykułu (Holtorf, 1996, s. 121; Żuk, 2015, s. 80-104).

Termin „krajobraz pamięci” pierwotnie pojawił się w ramach dyskursu socjologicznego. Na gruncie polskim kategorię tę wydzielił Sławomir Kapralski, nawiązując w swojej pracy do Arjuna Appaduraina. Krajobraz pamięci charakteryzuje jako twór o wielowymiarowym kompleksie znaczeń, którego postrzeganie jest niejednorodne, zależne od różnych czynników, dodatkowo ma on charakter wyobrażony, ponieważ „mimo iż krajobraz pamięci może przybierać formy materialne, konstytuuje się on poprzez wyobrażenia tych, którzy się do niego odnoszą" (Kapralski, 2010, s. 27). To obszar, na którym wytwarza się tożsamość, ale i, jak również zauważa Elżbieta Rybicka, przestrzeń gromadzi wiele pamięci, często o „skonfliktowanym” charakterze. Jak stwierdza badaczka, jest to sfera swoistej „,walki o władzę symboliczną" (Rybicka, 2011, s. 203).

Beata Frydryczak stwierdziła, że samo „miejsce pamięci” nie przysparza większych problemów definicyjnych. Jednak zadaniem trudniejszym jest zdefiniowanie w tych kategoriach (podanych przez P. Nora) krajobrazu i środowiska naturalnego. Badaczka stawia sobie pytanie, czy krajobraz może być uznany za miejsce pamięci? I stwierdza, powołując się na Roberta Trabę (2009) oraz Simona Schama (1996), że 
kategoria ta - krajobraz kulturowy - może uchodzić za medium pamięci kulturowej. P. Nora doszedł do wniosku, że jeśli dany krajobraz ,funkcjonuje w ramach pamięci kulturowej" (Nora, za: Frydryczak, 2015, s. 111), to można go uznać za krajobraz pamięci. Z kolei J. Assmann stwierdza, że „nawet całe krajobrazy - i szczególnie krajobrazy - służą jako medium pamięci kulturowej; nie przez umieszczenie w nich znaków [...] lecz przez podniesienie całości do rangi znaku, czyli przez semantyzację" (Assmann, 2009, s. 92). Zasadą rozpatrywania danej przestrzeni w kategoriach „krajobrazu pamięci” jest obecność w jej obrębie „czegoś”, co tę przestrzeń jednoznacznie identyfikuje. Sam krajobraz może nabyć dodatkowe wartości i znaczenia, a dzięki temu stać się częścią określonej przestrzeni kulturowej. Badacz podaje przykłady krajobrazów pamięci, którymi są: Rzym, Ziemia Święta itp. Nazywa je „topograficznymi tekstami pamięci kulturowej” (Assmann, 2009, s. 92; Frydryczak, 2015, s. 111-113).

Wracając jeszcze do idei „miejsca”, takie ujęcie mówi, że jest ono w relacji zarówno z okolicą, jak i z całym krajobrazem, jednocześnie będąc integralną jego częścią. Pamięć może się wyrażać w krajobrazie przez pozostawione w jego obrębie ślady powstałe w wyniku ludzkiej aktywności, które są czytelne współcześnie, funkcjonując w topografii krajobrazu. W takim ujęciu krajobraz zdaniem B. Frydryczak będzie się jawił jako:

przestrzeń, która „gromadzi”, „magazynuje” [...] „zapisuje” ślady człowieka [...] jeśli uznamy, że krajobraz zawiera w sobie pamięć niepodmiotową, to możemy mówić o nim jako o środowisku pamięci, w którym zachowane są ślady życia i działań poprzednich pokoleń, których aktywność wpisuje się w sensie materialnym i symbolicznym w przestrzeń aktualnej aktywności człowieka. To ślady, których nie obejmuje ani wspomnienie, ani pamięć kulturowa i które nie są podporządkowane czasowi historycznemu, lecz naturalnemu, tworząc środowisko pamięci. Środowisko pamięci, czyli przestrzeń, która zawiera zarówno materialne, jak i nie ludzkie i nie-ludzkie artefakty przeszłości. (Frydryczak, 2015, s. 120)

Owe ślady, znaki „zapisane” w krajobrazie zyskują funkcję swoistego medium, przez które wyraża się pamięć. Tak więc pamięć krajobrazu będzie odnosiła się do topograficznego miejsca, z takimi właśnie śladami, które pozwolą na zastosowanie względem nich tej kategorii. W takim ujęciu uwidacznia się wyraźniej palimpsestowy charakter krajobrazu kulturowego (Frydryczak, 2015, s. 120-121).

Krajobraz stanowi kategorię o wielowymiarowym charakterze. „Splata [...] naturę z kulturą, estetykę i ideologię, materialne i psychiczne, historię i przestrzeń [...] jest przede wszystkim generatorem pytań o nasze miejsce w świecie" (Rybicka, 2015). Współcześnie cieszy się sporym zainteresowaniem badawczym na gruncie różnych dyscyplin naukowych, z których archeologia często „czerpie pomysły” w podejściu do tego zagadnienia. $\mathrm{Z}$ racji jego charakteru ciężko jednoznacznie go zdefiniować, jednak na potrzeby moich rozważań za krajobraz kulturowy uznaję 
realnie istniejącą przestrzeń, która stanowi konstrukcję społeczną o wymiarze historycznym, czyli podlega zmianom w czasie. Poszczególne krajobrazy kulturowe składają się z miejsc - znaczących przestrzeni. Owe miejsca, jak i całe krajobrazy mają wymiar realny, ale i symboliczny. Cechuje je własna i wielowymiarowa czasowość. Za jedną z podstawowych funkcji krajobrazów kulturowych należy przyjąć przechowywanie pamięci kulturowej. Przy czym krajobrazy mogą zawierać wiele takich pamięci - mają charakter palimpsestowy. W końcu należy przyjąć, że poszczególne elementy krajobrazu, obiekty itp. mogą lub mogły pełnić role społeczne, wywierać istotny wpływ na podejmowane w ramach określonych społeczności działania. Prowadząc badania krajobrazowe, należy w końcu pamiętać, że mają one indywidualny, subiektywny charakter. Badając przeszły krajobraz, robimy to z punktu widzenia teraźniejszości i naszej kultury, a dotarcie do obiektywnej prawdy, czy rekonstrukcja obiektywnej wizji przeszłości jest niemożliwa.

\section{STANOWISKA/REGION W OKOLICY NIAUX JAKO „KRAJOBRAZ PAMIĘCI”}

Jaskinie Niaux i La Vache znajdują się w środkowej części Pirenejów w departamencie Ariège w dolinie Vicdessos, na południe od miejscowości Tarascon-sur-Ariège. Oddalone są od siebie około $500 \mathrm{~m}$. La Vasche znajduje się na lewym brzegu doliny, a Niaux na prawym. Otaczające ten region wapienne góry wznoszą się do 1100 metrów. Pobliskie tereny charakteryzują się gęstym zasiedleniem w okresie środkowego, a przede wszystkim późnego etapu rozwoju kultury magdaleńskiej. $\mathrm{W}$ promieniu około $7 \mathrm{~km}$ od miejscowości Tarascon-sur-Ariège ( $2 \mathrm{~km}$ od La Vache) zlokalizowano co najmniej 5 jaskiń z malowidłami oraz liczne stanowiska ze śladami pobytu owej ludności (Pailhaugue, 1998, s. 386; Hitchcock, 2014a; Sorriaux, Rouzaud, Wahl, 2017). Pisząc o „krajobrazie pamięci”, należy na początku skoncentrować się na wydzieleniu takich jego elementów, które ów krajobraz identyfikują, nadają mu rangę „krajobrazu pamięci”. Mowa tu o „miejscach pamięci”.

\section{JASKINIA W NIAUX JAKO PRAHISTORYCZNE „MIEJSCE PAMIĘCI"}

Odwołując się do koncepcji P. Nory, aby można było przypisać danemu obiektowi rangę „miejsca pamięci”, musi je cechować „wola pamiętania”, konieczny jest również upływ czasu, dostosowanie owej rzeczywistości do zmienionych/zmieniających się warunków społecznych, czyli kreowania w jej ramach często nowych znaczeń. Ostatnią zasadą jest zerwanie z „rzeczywistością pamięci” (Nora, 1996b, s. 14-16, za: Żuk, 2015, s. 79-84). Badacz ten, co istotne dla moich rozważań, 
stwierdził, że w ramach społeczności pradziejowej i przez jej odmienne postrzeganie czasu i przestrzeni nie miała prawa funkcjonować przestrzeń, którą można by określić jako „miejsce pamięci”.

Odmienny pogląd zaprezentował C. Holtorf, który jako pierwszy na gruncie archeologii zajął się, w latach 90. XX wieku, kategorią „miejsc pamięci”. Jako miejsca pamięci zinterpretował on megality znajdujące się w Meklemburgii-Pomorzu. Stwierdzenia badacza dotyczą jego zdaniem błędnego mniemanie P. Nory, że w stosunku do obiektów archeologicznych nie można mówić o intencji/woli pamiętania, ponieważ np. „,monumenty są tą częścią kultury, która [...] chce być widziana, zachowana i zapamiętana przez współczesne oraz przeszłe pokolenia. Monument jest ustanowionym znakiem, który w trwałej formie koduje pewien przekaz w celu porozumienia się z ludźmi [...] jest zaprojektowany po to, aby przetrwać teraźniejszość i umożliwić kulturową komunikację" (Holtorf, 1996, s. 121, za: Żuk, 2015, s. 82). Funkcję tę zapewne pełniły także i inne obiekty archeologiczne, choćby paleolityczne jaskinie z malowidłami i rytami, ponieważ, jak stwierdza L. Żuk, społeczności pradziejowe „nie żyły w jakiejś ponadczasowej rzeczywistości, ale miały świadomość upływającego czasu i przemijania" (Żuk, 2015, s. 80-104). Badacze ci, co prawda, swoje rozważania prowadzili, opierając się na artefaktach neolitycznych, w której to epoce ludność cechowała się osiadłym trybem życia. Jednak moim zdaniem stanowisko La Vache, będące obozowiskiem sezonowym, stanowiło miejsce stałego powrotu, co więcej, znaleziony w niej materiał nie należał jedynie do inwentarza ludności kultury magdaleńskiej, ale $\mathrm{w}$ jego obrębie odkryto także artefakty przypisane społeczności kultury azylskiej - chronologicznie późniejszej (Pailhaugue, 1998, s. 386). Fakt ten jest istotny, ponieważ koreluje także z pozyskanymi z jaskini Niaux datami, do czego jeszcze wrócę.

Zależność między tymi dwoma stanowiskami jest istotna, ponieważ najprawdopodobniej obie jaskinie były wykorzystywane przez tę samą ludność, choćby przez pewien czas ich współistnienia. Społeczność ta w jednej z nich obozowała, natomiast drugą przeznaczyła na swoiste, jak to często pojawia się w literaturze przedmiotu, ,paleolityczne sanktuarium”, w którym nie odnaleziono śladów zamieszkiwania. O zależności między tymi dwoma stanowiskami świadczy ich datowanie, dodatkowo sam fakt niewielkiej odległości między nimi stanowić może dowód, że to właśnie ludność magdaleńska obozująca w La Vache była „realizatorem” założenia w Niaux (Hitchcock, 2014a; O'Hara, 2014, s. 73, 82-83).

Pozyskane dane z Niaux:

bezpośrednio datowanie metodą AMS próbek węgla drzewnego użytego do wykonania farb pobranego $\mathrm{z}$ pięciu malowideł określiło ich wiek na od $13850 \pm 150 \mathrm{BP}$ $($ GifA-92501) $\approx 15292 \pm 184$ BC do $12440 \pm 190$ BP (GifA-91173) $212624 \pm 443$ BC: bizona z Czarnego Salonu (K1/FR 14, K4/FR 132, 217-222, 224) datowano na $12890 \pm$ \pm 160 BP $($ GifA-91319) $13748 \pm 646$ BC, a próbka ze znajdującej się tuż obok niego na 
ścianie skalnej czarnej linii dała rezultat $13060 \pm 200$ BP (GifA-92499) $\approx 14054 \pm 612$ BC. (Wierzbicki, 2012, s. 106-107, tam dalsza literatura)

Malowidła te zalicza się do stylu IV według A. Leroi-Gourhana i uznaje się je za jednorodne stylowo i że nie były uzupełniane późniejszymi malowidłami (Gąssowski, 2008, s. 51, 57; Płonka, 2012, s. 179). Przebadany i wydatowany materiał zaliczany do kultury magdaleńskiej z La Vache, jak podaje N. Pailhaugue, przedstawia się następująco:

z laboratorium w Groningue na zlecenie R. Robert:

Gr $202512540 \pm 105$ BP warstwa II

Gr 2026: warstwa $12850 \pm 140$ BP IV

Nowe daty wykonane [...] przez laboratorium Gif-sur-Yvette [...] potwierdziły poprzednie: GIF. $760312800 \pm 140$ BP warstwa II. Niedawno uzyskane daty [...] w laboratorium Gif-sur-Yvette:

Plac 269, głębokość 109 cm: $13490 \pm 120$ BP

Plac 71, głębokość 59,5 cm: $13770 \mathrm{BP} \pm 140$

Plac 71 głębokość $115 \mathrm{~cm} 13130 \pm 650$ BP. (Pailhaugue, 1998, s. 386)

Dodatkowo barwniki pozyskane z Niaux i La Vache cechują się podobną recepturą (O’Hara, 2014, s. 73). O’Hara (2014, s. 83), badając zależność między tymi obiektami, doszedł do wniosku, że w materiale kostnym i reprezentującymi go gatunkami a tymi przedstawionymi na ścianach jaskini Niaux ,istnieje pewna korelacja”, a na tej podstawie stwierdził, ,że malarze jaskini nie wykuwali zwierząt znikąd w jakimś szamańskim transie lub rytuale. Raczej ich malowidła odzwierciedlają rzeczywiste otoczenie [...] dokładnie odzwierciedlają klimat w momencie ich utworzenia".

W tym miejscu należy wrócić jeszcze do odkrytego w La Vache materiału o późniejszej metryce, zaliczanego do inwentarza kultury azylskiej, jednostki funkcjonującej w okresie, kiedy tradycja tworzenia naskalnej sztuki jaskiniowej dobiegła końca (Kozłowski, 1999, s. 109, 110). Natomiast pozyskane daty z fragmentów łuczyw trzech innych próbek z Niaux ,obejmowały przedział od $10150 \pm 200 \mathrm{BP}$ $($ Gif-1940) $\approx 9852 \pm 392$ BC do $9850 \pm 230$ BP (Gif-1937) $\approx 9347 \pm 393$ BC (Wierzbicki, 2012, s. 106-107). Co może dowodzić, że jaskinia ta stanowiła miejsce znane i odwiedzane jeszcze tysiące lat po wykonaniu w niej naskalnych malowideł i rytów (Wierzbicki, 2012, s. 106-107, tam dalsza literatura). A. Beltrán Martínez wspomina, że podczas badań R. Simonnet w tym obiekcie odkryto ceramikę zaliczaną do epoki brązu (Beltrán Martínez, 1973, za: Hitchcock, 2014b).

Należy w tym miejscu przypomnieć, co jest główną funkcją „miejsc pamięci”. Jak samo określenie wskazuje, jest to upamiętnianie, swoiste przechowywanie owej pamięci, która wiąże się z tożsamością danej grupy. Dodatkowo istotne jest ich społeczne ukształtowanie oraz dostrzegalna także w tym przypadku swoista relacja 
z pobliską okolicą - krajobrazem przekształconym kulturowo. Tradycja ,zakładania" czy trafniej przekształcania obiektów jaskiniowych przez umieszczanie w ich obrębie malowideł, rytów, a także często innych elementów kulturowych trwała ponad dwadzieścia tysięcy lat. Tak więc stanowisko Niaux wpisuje się w szerszy kontekst kulturowy, jest elementem mającym zapewnić jego ciągłość, a przez to i upamiętnić, zapewnić trwałość tradycji czy też stanowić nośnik pewnego sposobu widzenia świata. Wiadomo też, że założenia owych obiektów cechuje przemyślana organizacja ich przestrzeni (Clottes, 1995, s. 101, 159, rys. 18; Clottes, Lewis-Williams, 2009, s. 75; Robert, 2010-2011, s. 330-331). J. Clottes, D. Lewis-Williams wysunęli nawet wniosek, że duża sala w Niaux (tak jak i w wielu innych jaskiniach, gdzie znaleźć można podobne) z bardziej staranniej wykonanymi malowidłami i sporą przestrzenią mogła być miejscem, gdzie gromadziła się większa grupa ludzi ,ponieważ pewne jest, że tradycja trwała ponad dwadzieścia tysięcy lat i że wymagało to przekazywania jej dogmatów, możliwe, że sale te mogły odgrywać jakąś rolę w tym procesie" (Clottes, Lewis-Williams, 2009, s. 229). Chociaż trudno potwierdzić takie stwierdzenie, to upamiętniająca funkcja owych obiektów wydaje się oczywista, a odmienny sposób postrzegania czasu i przestrzeni w ramach owych społeczności jej nie wyklucza. Dodatkowo trud włożony w ich realizację poświadcza, że stanowiły one dużą wartość dla społeczności i że odczuwała ona potrzebę ich tworzenia. Odmienność stylów tych malowideł i ich chronologii także to potwierdza. Stanowiły więc część powielanego schematu, przekazywały określony sposób postrzegania świata, ale można stwierdzić za L. Żuk, że społeczności pradziejowe miały poczucie upływającego czasu. Odczuwały potrzebę tworzenia swoistych nośników własnej tradycji, aby ją upamiętnić. Musiały stanowić one „miejsce pamięci” choćby dla społeczności pradziejowej, która pozostawiła swoje ślady w niej znacznie później, niż powstało to założenie. W czasach, w których sztuka naskalna w tym rejonie przestała być tworzona.

Powracając jeszcze do zasad P. Nory, to nawet w kontekście społeczności pradziejowej można dostrzec, że zostały one spełnione. Po pierwsze da się stwierdzić, że motywacją realizacji określonej jaskini ze sztuką pradziejową była ,wola pamiętania”, czyli przekazanie, utrwalenie przyjętej tradycji, powielenie schematu. Następnym wymogiem miał być upływ czasu, który również został spełniony. Oczywiste wydaje się także to, że w tak długo trwającej tradycji warunki społeczne ulegały przekształceniom, a owe obiekty, użytkowane przecież tak długo, musiały się do nich dostosować. Ostatnią zasadą miało być zerwanie z ,rzeczywistością pamięci”, co także jest prawdopodobne w przypadku Niaux. Pozyskane daty pokazują ogromną rozbieżność czasową między wykonaniem malowideł oraz czasem w pradziejach, w których pozostawiono ślady po jej odwiedzaniu. Można więc przyjąć, że sytuacja „zerwania z rzeczywistością pamięci” także mogła zaistnieć, a jaskinia Niaux stanowiła swoiste ,miejsce pamięci” już w pradziejach. 


\section{KOMPLEKS JASKIŃ W OKOLICY NIAUX JAKO WSPÓLCZESNE „MIEJSCE (A) PAMIĘCI”/ „KRAJOBRAZ PAMIĘCI”}

Krajobraz kulturowy stanowi konstrukcję społeczną oraz kulturową i należy przyjąć, że w jego konstruowaniu istotne znaczenie odgrywa pamięć (Frydryczak, 2015, s. 121). Natomiast „krajobraz pamięci” stanowi obszar, w obrębie którego odnaleźć można miejsca/znaki itp., które jako takie będą go identyfikować w ramach szerszej przestrzeni kulturowej. Będzie on stanowił obszar, przez który i w którym wytwarza się tożsamość danej społeczności, gdzie odnaleźć można rzeczy stanowiące ważny symbol/znak lub które budzą emocje. Może on więc stanowić miejsce o wymiarze realnym, natomiast materialnej formie jednak o wyobrażonym charakterze, zależnym od tego, kto się do niego odnosi (Assmann, 2009, s. 92; Kapralski, 2010, s. 27; Frydryczak, 2015, s. 111-113; Minta-Tworzowska, 2015a, s. 21). Jego znaczenie i postrzeganie też może być i jest różne, bo przecież obejmuje obszar, który stanowi konstrukcję antropologiczną, społeczną i historyczną przechowującą pamięć czy raczej wiele pamięci kulturowych, które oczywiście nie przyjmują form prostych wspomnień - ma charakter palimpsestowy (Frydryczak, 2015, s. 120-121; Rybicka, 2015).

Z powyższych rozważań wynika, że aby móc scharakteryzować jakąś przestrzeń/krajobraz jako „krajobraz pamięci”, należy wykazać, że znajdują się na jego przestrzeni/obszarze miejsca/znaki/symbole, przez które „,przemawia pamięć”, które pozwalają na taką jego interpretację. Za takie w owej pracy uznawane są jaskinie w La Vache i Niaux, które z perspektywy teraźniejszej można interpretować jako „miejsca pamięci”.

Współczesne podejście do tych stanowisk jest zgodne z definicją P. Nora dotyczące „miejsc pamięci”, za które uważa „każdy istotny byt, zarówno materialny, jak i niematerialny w swej naturze, który wysiłkiem ludzkiej woli lub poprzez pracę czasu stał się symbolicznym elementem dziedzictwa pamięci danej społeczności" (Nora 1996a, s. XVII, za: Żuk, 2015. s. 79-81). Z całą pewnością są one postrzegane jako element dziedzictwa kulturowego. Sposób podejścia do tych zabytków jest nacechowany ,wolą pamiętania”. Poświadczają ją choćby prowadzone badania, opieka nad tymi monumentami. Dobrym przykładem ,woli pamiętania” jest choćby motyw przeprowadzonych w 2006 r. działań w Niaux, których efektem było udostępnienie turystom najgłębszych partii jaskini w setną rocznicę odkrycia tego zabytku (Le Guillou, Alard, Vaginay, 2007, s. 5, 16). Dodatkowo oba te obiekty zostały wpisane do rejestru zabytków, Niaux w 1911 r. (http://www.culture... 1=PA00093895), a La Vache w 1952 r. (http://www.culture...1=PA00093776), przez co są też objęte ochroną ze strony państwa. Definicja zabytku w prawie francuskim z 1913 r. definiowała go jako „dzieło stworzone ręką człowieka, wzniesione celowo w zamiarze zachowania zawsze obecnej i żyjącej w świadomości przyszłych pokoleń pamięci działania człowieka czy określonego przeznaczenia owego dzieła" (Riegl, 1903 [1984], s. 35 i 87, za: Drela, 2009, s. 115). 
Wracając do wyznaczników P. Nory, do kolejnych należą upływ czasu oraz „zdolność do przemiany, potencjał do kreowania nowych znaczeń i treści w zmieniających się warunkach społecznych" (Nora, 1996b, s. 15). Upływ czasu jest oczywisty, także z punktu widzenia współczesności. Znaczenia oraz treści, które odczytujemy, i to, jak pojmujemy owe jaskinie, są z całą pewnością odmienne, niż były one dla ich twórców. $Z$ całą pewnością nie jesteśmy w stanie ich zrekonstruować, możemy jedynie podejmować takie próby, a jednak monumenty te, stanowiąc ważny element współczesnej kultury, zyskały nowe znaczenie. $Z$ całą pewnością nastąpiło także zerwanie $\mathrm{z}$,rzeczywistością pamięci”. Miejsca te zostały na nowo odkryte w XX wieku. Jest jednak prawdopodobne, że były wielokrotnie odkrywane. Towarzyszące paleolitycznym malowidłom graffiti w jaskini Niaux mogą to poświadczać. Uwidacznia się w tym przypadku także palimpsestowy charakter owych miejsc. Stanowiło ono obiekt zainteresowania człowieka od czasów pradziejowych, można powiedzieć, że jaskinie te i obszar je otaczający to swoisty „magazyn śladów przeszłości”. Sięgające początków XVII wieku graffiti także są ich częścią. Na owych zapisach często pojawiały się daty, co świadczyć może o chęci zapamiętania przez ich twórców pozostawienia śladu swojego pobytu, tak jak uczynili to wcześniejsi „goście” (Lamiable, 2006, s. 11-33). Liczne odwiedziny tego miejsca poświadcza liczba pozostawionych śladów - ponad tysiąc. Znajdujące się na niektórych napisach daty poświadczają, że „zwiedzanie” odbywało się w 1561 (?), 1586 r., w latach 1610-1692 oraz później w XVIII i XIX wieku. Niekiedy graffiti są na tyle czytelne, że można stwierdzić, kim była osoba, która je po sobie pozostawiła. Ciekawym przykładem jest tu „turysta” z 1660 r. Ruben de la Vialle. Zlokalizowano trzy pozostawione przez niego podpisy, w każdym z nich zawarł również datę pobytu.

Kim był? Rodzina Ruben albo Rubent to znana i ważna miejscowa rodzina mieszczańska i kupiecka, z której wywodziło się wielu znanych księży. Swój podpis zostawił Antoine Ruben (ur. 6 lipca 1636 r.), dziedzic i kontynuator kariery swojego wielkiego dziadka Pierre'a Ruben de Lombre'a, adwokata zasiadającego w parlamencie w Bordeaux, zajmującego wiele ważnych stanowisk; sam Antoine poszedł w jego ślady, ale sprawował tę funkcję w Tuluzie. Miał prawo do używania nazwiska Ruben de la Vialle lub Ruben de Lombre. W wieku 24 lat znalazł się w grocie Niaux. (Minta-Tworzowska, 2018, s. 50)

W XVII wieku jaskinie z malowidłami stanowiły obiekt zainteresowania głównie w kręgu miejscowych elit, o czym świadczą graffiti. Traktowano je zapewne jako swoistą własność, dziedzictwo. Cel odwiedzin owych obiektów zapewne ulegał zmianom na przestrzeni wieków. Dopiero w drugiej połowie XIX wieku zaczęto dostrzegać ich znaczenie historyczne oraz podejmować próby ochrony. Cel wykonywania owych śladów był zapewne także odmienny w różnych epokach. Jak stwierdziła D. Minta-Tworzowska: 
Pierwsi wizytujący w czasach nowożytnych traktowali jaskinie jako środowisko „ciemne”, nieznane, jako „galerie osobliwości”. Starali się tym napawać, ale też to przełamać. Kolejni starali się „humanizować” przestrzeń jaskini poprzez zostawianie znaków [...] Z czasem tej humanizacji dokonywali poprzez konstruowanie w jaskini „ścian pamiątek/pamięci"; ich apogeum to całe galerie upamiętniające wizyty w XIX wieku. (MintaTworzowska, 2018, s. 53)

W końcu z całą pewnością jaskinie stanowią przestrzeń, która pobudzała wyobraźnię, ponieważ swoją formą nawiązują do idei świata podziemnego. W XVII wieku funkcjonowały różne sekretne ugrupowania/bractwa „które mocno nawiązują do treści symbolicznych jaskini, zbierając się często w miejscach przypominających nastrojem jaskinię [...]. Takim miejscem o zbliżonym klimacie była zapewne jaskinia Niaux. Też była miejscem zakazanym, miejscem przemiany" (Minta-Tworzowska, 2018).

Istotną cechą „miejsc” i „krajobrazów” pamięci wydaje się pobudzanie emocji, co z całą pewnością ma miejsce w przypadku tych stanowisk, a czego dowodem mogą być choćby pozostawione w Niaux graffiti stanowiące jednocześnie nowe nośniki pamięci, tym razem należące już do odmiennej kultury.

Obie jaskinie można rozpatrywać w kategorii „miejsca pamięci”, które postrzegane w szerszym kontekście przestrzenno-kulturowym stanowią ważne elementy „krajobrazu pamięci” wpisującego się we współczesną przestrzeń - krajobraz kulturowy - i stanowiące jej ważny element. Powyższe rozważania na temat zależności między La Vache i Niaux pokazują, że te dwa stanowiska mogą, a nawet powinny być traktowane łącznie. W takim ujęciu można badać je właśnie w kontekście „krajobrazu pamięci”.

Nawiązując do definicji „krajobrazu pamięci” S. Kapralskiego, obszar w departamencie Ariégie, dolinie Vicdessos, gdzie znajdują się dwa pradziejowe stanowiska: La Vache i Niaux, wydaje się być z nią zgodny, ponieważ jawi się jako przestrzeń o wielowymiarowym kompleksie znaczeń, której postrzeganie jest niejednorodne, zależne od różnych czynników. Dodatkowo, co wydaje się oczywiste, ma charakter wyobrażony, zależny od tego, kto się do niego odnosi (Kapralski, 2010, s. 27). Nawiązując z kolei do pracy E. Rybickiej i jej rozumienia kategorii „krajobrazu pamięci", który postrzega jako przestrzeń, w obrębie której wytwarza się tożsamość i która gromadzi wiele pamięci (Rybicka, 2011, s. 203 ), cechy te również można odnieść do omawianego regionu.

Podjęta w niniejszym artykule próba interpretacji pradziejowych stanowisk archeologicznych w kontekście „miejsc pamięci” oraz „krajobrazu pamięci” wpisuje się w swoistą funkcjonującą aktualnie modę badawczą. Współcześnie dostrzec można spore zainteresowanie koncepcją „miejsc pamięci”, krajobrazu czy najnowszą „krajobrazu pamięci”. Powyższe rozważania miały na celu ukazanie, że kategorie te można rozpatrywać również $\mathrm{w}$ odniesieniu do stanowisk paleolitycznych. Badając 
jaskinię w Niaux, jako pradziejowe „miejsce pamięci”, odwołano się do wymienionych przez P. Norę elementów, zasad, które badacz uznał za niezbędne do spełnienia, aby dane miejsce można było określić mianem „miejsca pamięci” i uznano, że jaskinia Niaux mogła stanowić swoiste „miejsce pamięci” już w pradziejach. Sytuacja wydaje się jeszcze bardziej oczywista w przypadku rozpatrywania zarówno jaskini Niaux, jak i sąsiadującej z nią groty La Vache jako „miejsc pamięci” ze współczesnego punktu widzenia.

W pracy przyjęto, że „krajobraz pamięci” to obszar, gdzie odnaleźć można miejsca/znaki itp., które będą go identyfikować w ramach szerszej przestrzeni kulturowej. Dodatkowo jest to przestrzeń, przez którą i w której uwidacznia się tożsamość danej społeczności. W niej to znajdują się rzeczy stanowiące ważny symbol/znak lub które budzą emocje. „Krajobraz pamięci” stanowi obszar o realnej, materialnej formie, jednak o wyobrażonym charakterze, zależnym od tego, kto się do niego odnosi. Tak więc jego znaczenie i postrzeganie jest różnorodne, ponieważ to konstrukcja społeczna, antropologiczna, historyczna „magazynująca” wiele pamięci kulturowych, które nadają mu charakter palimpsestowy (Assmann, 2009, s. 92; Kapralski, 2010, s. 27; Frydryczak, 2015, s. 111-113, 120-121; Minta-Tworzowska, 2015a, s. 21; Rybicka, 2015). Jaskinie La Vache i Niaux interpretowane z perspektywy teraźniejszej jako „miejsca pamięci”, rozpatrywane w szerszym kontekście przestrzenno-kulturowym, stanowią ważne elementy „krajobrazu pamięci”, które jednoznacznie go identyfikują i nadają mu taką rangę. Dodatkowo przedstawione zależności między tymi dwoma stanowiskami pokazują, że mogą czy wręcz powinny być traktowane łącznie. W takim ujęciu można badać je właśnie w kontekście „krajobrazu pamięci” cechującego się palimpsestowym charakterem, wielowymiarowym, niejednorodnym kompleksem znaczeń oraz wyobrażonym charakterem.

W niniejszej pracy omówiono czy raczej wyróżniono jedynie dwa znaczące miejsca $\mathrm{z}$,krajobrazu kulturowego” w okolicach Niaux. Widoczna jest tu potrzeba dalszych badań i ujęcia ich w szerszym kontekście przestrzennym. Wiadomo, że w promieniu około $7 \mathrm{~km}$ od miejscowości Tarascon-sur-Ariège (2 $\mathrm{km}$ od La Vache) zlokalizowano co najmniej 5 jaskiń z malowidłami i liczne stanowiska ze śladami pobytu ludności kultury magdaleńskiej (Pailhaugue, 1998, s. 386; Hitchcock, 2014a).

\section{BIBLIOGRAFIA}

Assmann, J.

2001 Der Tod als Thema der Kulturtheorie. Frankfurt am Main: Suhrkamp Verlag AG.

2003 Pamięć zbiorowa i tożsamość kulturowa. Borussia, 29, 11-16.

2008 Pamięć kulturowa. Pismo, zapamiętywanie i polityczna tożsamość w cywilizacjach starożytnych (A. Kryczyńska-Pham, thum.). Warszawa: Wydawnictwo Uniwersytetu Warszawskiego. 
2009 Kultura pamięci. W: M. Saryusz-Wolska (red.), Pamięć zbiorowa i kulturowa. Wspótczesna perspektywa niemiecka (A. Kryczyńska-Pham, tłum.) (s. 59-99). Kraków: Universitas.

Banaszek, Ł.

2015 Przeszłe krajobrazy w chmurze punktów. Poznań: Wydawnictwo Naukowe UAM.

Beltrán Martínez, A.

1973 La cueva de Niaux (Monografias arqueologicas). Departamento de Prehistoria y Arqueologia. Fac. Letras

Clottes, J.

1995 Les Cavernes de Niaux. Art. prehistorique en Ariége (s. 101, 159, rys. 18). Paris: Errances.

Clottes, J., Lewis-Williams, D.

2009 Prehistoryczni szamani. Trans $i$ magia $w$ zdobionych grotach (A. Gronowska, thum.) (s. 75). Warszawa: Wydawnictwa Uniwersytetu Warszawskiego.

Frydryczak, B.

2015 Krajobraz jako miejsca i nie-miejsca pamięci. Próba ujęcia. W: B. Gediga, A. Grossman, W. Piotrowski (red.), Miejsca pamięci. Pradzieje, średniowiecze i wspótczesność (s. 111-124). Biskupin - Wrocław: Muzeum Archeologiczne w Biskupinie, Komisja Archeologiczna Wrocławskiego Oddziału PAN.

Gąssowski, J.

2008 Prahistoria sztuki. Warszawa: TRIO.

Halbwachs, M.

2008 Spoteczne ramy pamięci (M. Król, tłum., wyd. 2). Warszawa: PWN.

Holtorf, C.

1996 Towards a Chronology of Monuments: Understanding Monumental Time and Cultural Memory. Journal of European Archaeology, 4, 119-152.

Ingold, T.

1993 The temporality of the landscape. World Archaeology, 25(2), 152-174.

Kapralski, S.

2010 Pamięć, przestrzeń, tożsamość. Próba refleksji teoretycznej. Warszawa: Scholar.

Kordys, J.

1991 Mózg i znaki. Warszawa: Państwowy Instytut Wydawniczy.

Kowalski, A. P.

1999 Symbol w kulturze archaicznej. Poznań: Wydawnictwo Naukowe Instytutu Filozofii UAM.

Kuczyńska, A.

2011 Analiza górnopaleolitycznych przedstawień antropomorficznych z obszaru Europy i Syberii w kontekście kultury typu magicznego. Zeszyty Naukowe Towarzystwa Doktorantów Uniwersytetu Jagiellońskiego. Nauki Społeczne, 2, 50-60.

Kozłowski, J. K. (red.)

1999 Encyklopedia historyczna świata, t. 1: Prehistoria. Kraków: Opres.

Kritzman I. D. (red.)

1996-1998 Realms of Memory (t. 1-3). New York: Columbia University Press.

Lamiable, J.-N.

2006 La grotte de Niaux au cours des Temps modernes. Etude préliminaire des graffitis de la grotte de Niaux et de leurs auteurs. Préhistoire, Art et Sociétés, 61, 11-33. 
Le Guillou, Y., Alard, P., Vaginay, M.

2007 Visites au réseau Clastres. Préhistoire. Art et Sociétés, 62, 5-18.

Leroi-Gourhan, A.

1966 Religie prehistoryczne (I. Dewitz, thum.). Warszawa: PWN.

Marciniak, A.

2012 Teoria w archeologii. W: S. Tabaczyński, A. Marciniak, D. Cyngot, A. Zalewska (red.), Przeszłość społeczna. Próba konceptualizacji (s. 84-116). Poznań: Wydawnictwo Poznańskie.

Minta-Tworzowska, D.

2015a O „użyteczności” rozważań nad miejscami i krajobrazami pamięci w archeologii. W: B. Gediga, A. Grossman, W. Piotrowski (red.), Miejsca pamięci. Pradzieje, średniowiecze i wspótczesność (s. 13-31). Biskupin - Wrocław: Muzeum Archeologiczne w Biskupinie, Komisja Archeologiczna Wrocławskiego Oddziału PAN.

2015b Granice poznania dzieła malarskiego jako dzieła „sztuki” pradziejowej. Na kanwie rozważań Romana Ingardena. Folia Praehistorica Poznaniensia, 20, 339-356.

2018 Przestrzenny aspekt umieszczenia graffiti w grotach z paleolitycznymi „obrazami”. Przykład jaskini Niaux. W: B. Gediga, A. Grossman, W. Piotrowski (red.), Inspiracje i funkcje sztuki pradziejowej i wczesnośredniowiecznej (s. 39-60). Biskupin - Wrocław: Muzeum Archeologiczne w Biskupinie, Komisja Archeologiczna Wrocławskiego Oddziału PAN.

Nora, $\mathrm{P}$.

1974 Mémoire collective. W: J. Le Goff, P. Nora (red.), Faire de l'histoire (s. 41). Paris: Gallimard.

1996a From Lieux de memoire to Realms of Memory. W: L. D. Kritzmann (red.), Realms of Memory. Conflicys and Divisions (s. XV-XIV). New York: Columbia University Press.

1996b General Introduction: Between Memory and History. W: L. D. Kritzmann (red.), Realms of Memory. Conflicys and Divisions (s. 1-20). New York, NY: Columbia University Press.

2001 Czas pamięci (W. Dłuski, thum.). Res Publica Nowa, 7, 37-43.

O'Hara, K. D.

2014 Cave Art and Climate Change. Archway Publishing.

Pailhaugue, N.

1998 Faune et saisons d'occupation de la salle Monique au Magdalénien Pyrénéen, grotte de la Vache (Alliat, Ariège, France). Quaternaire, 9(4), 385-400.

Polkowski, P. L.

2016 Krajobraz i sztuka naskalna. W palimpseście egipskiej Oazy Dachla. Poznań: Muzeum Archeologiczne.

Płonka, T.

2012 Kultura symboliczna społeczeństw towiecko-zbierackich środkowej Europy u schytku paleolitu. Wrocław: Wydawnictwo Uniwersytetu Wrocławskiego.

Riegl, A.

1903 Le culte moderne des monuments. Son essence et sa genèse (s. 35, 87). Paris: Éditions du

[1984] Seuil.

Robert, E.

2010-2011 Signes, parois, espaces. Modalités d'expression dans le Paléolithique supérieur oust européen. W: J. Clottes (red.), Préhistorique art et societies. L'art pléistocéne dans le monde, „Préhistoire, Art et Sociétés” (t. 65-66, s. 330-331). 
Rybicka, E.

2011 Pamięć i miasto. Palimpsest vs. pole walki. Teksty Drugie, 5, 201-211.

2015 Krajobraz. Krótkie wprowadzenie. Herito, 19, 12-21.

Schama, S.

1966 Landscape And Memory. New York, NY: Vintage Books.

Szpociński, A.

2008 Miejsca pamięci (lieux de mémoire). Teksty Drugie, 4, 11-20.

Tilley, Ch.

1994 A Phenomenology of Landscape. Places, paths and monuments. Oxford: Berg Publishers.

Traba, R.

2009 Przeszłość w teraźniejszości. Polskie spory o historię na początku XXI wieku. Poznań: Wydawnictwo Poznańskie.

Trigger, B.

2007 A History of Archaeological Thought. Cambridge: Cambridge University Press.

Wierzbicki, J.

2012 Epoka kamienia w Europie znakami pocztowymi pisana. Popularyzacja archeologii w filatelistyce. Zielona Góra: Wydawnictwo Fundacji Archeologicznej.

Woźny, J.

$2000 \quad$ Symbolika przestrzeni miejsc grzebalnych $w$ czasach ciałopalenia zwłok na ziemiach polskich (od środkowej epoki brazu do środkowego okresu lateńskiego). Bydgoszcz: Wydawnictwo Uczelniane WSP.

Zalewska, A.

2015 Miejsca w pamięci. Stanowiska archeologiczne jako pola artykulacji pamięci w kontekście studiów i kategorii pamięcioznawczych. W: B. Gediga, A. Grossman, W. Piotrowski (red.), Miejsca pamięci. Pradzieje, średniowiecze i wspótczesność (s. 61-77). Biskupin - Wrocław: Muzeum Archeologiczne w Biskupinie, Komisja Archeologiczna Wrocławskiego Oddziału PAN.

Żuk, L.

2015 Rzeczywistość pamięci (milieu de mémoire) społeczności pradziejowych. W: B. Gediga, A. Grossman, W. Piotrowski (red.), Miejsca pamięci. Pradzieje, średniowiecze i wspótczesność (s. 79-109). Biskupin - Wrocław: Muzeum Archeologiczne w Biskupinie, Komisja Archeologiczna Wrocławskiego Oddziału PAN.

\section{Źródła elektroniczne}

Drela, M.

2009 Definicja zabytku nieruchomego w prawie polskim i francuskim. Pobrano z: http://www. nid.pl/upload/iblock/0c8/0c8466bcef508bc2ed359477984d6daa.pdf

Hitchcock, D.

2014a Grotte de la Vache in the Pyrenees was home for the artists of Niaux Cave. Pobrano z: http://donsmaps.com/grottevache.html

2014b Niaux - Grotte de Niaux Description and History. Pobrano z: http://donsmaps.com/ niauxart.html

http://www.culture.gouv.fr/public/mistral/merimee_fr?ACTION=CHERCHER\&FIELD_1=REF\&VA LUE_1=PA00093766

http://www.culture.gouv.fr/public/mistral/merimee_fr?ACTION=CHERCHER\&FIELD_1=REF\&VA LUE_1=PA00093895

Sorriaux, P., Rouzaud, F., Wahl, L.

2017 Niaux, Lombrive, Sabart. (Pyrénées ariègeoises). Pobrano z: http://www.schs09.com/ historique/niaux-lombrives-sabart 


\title{
THE INTERPRETATION OF THE PREHISTORIC SITES NIAUX AND LA VACHE AS "SITES OF MEMORY” AND "LANDSCAPE OF MEMORY”
}

\author{
S u m m a r y
}

The aim of the article was to apply the concept of "sites of memory" and "landscape of memory" to prehistoric sites. In contemporary humanities, "sites of memory" have become a popular subject of research on the international level. They are also very popular in archeology. In the humanistic discourse, the concept of a "landscape of memory" also appeared.

The Niaux and La Vache caves are located in the middle part of the Pyrenees in the department of Ariège in the Vicdessos Valley. They are about $500 \mathrm{~m}$ away from each other. La Vasche is located on the left bank of the valley and Niaux on the right bank. The nearby areas were characterized by dense colonization in the middle period, and above all, the late stage of Magdalenian culture development. Most likely, both caves were used by the same population, even if they coexisted for some time. This community camped in one of them, while the other one devoted a paleolithic sanctuary to its specific, as it often appears in the literature on the subject. The relationship between these two positions is confirmed by their dating, in addition the mere fact of a short distance between them can indicate this.

Referring to the concept of P. Nory, in order for a given object to be considered a "site of memory", it must be characterized by: "the will to remember", it is also necessary to pass time, adapt this reality to changed / changing social conditions, that is create in it often new meanings. The last principle is the break with the "reality of memory" (Nora, 1996b, p. 14-16, after: Żuk, 2015 , p. 79-84). It was considered that in the case of the Niaux cave, all of the above guidelines were met and the object itself could have been a ,place of remembrance" already in prehistory. It was found that the motivation for the implementation of the Niaux cave was "the will to remember". The tradition of transforming cave objects by placing within them murals, rites, and often other cultural elements, lasted over twenty thousand years (Clottes, Lewis-Williams, 2009, p. 229). Thus, the Niaux cave fits into the wider cultural context is an element to ensure its continuity, to commemorate, to ensure the durability of tradition, or to be a carrier of a certain way of seeing the world. The passage of time also took place. It also seems obvious that in such a long-lasting tradition social conditions have undergone transformations, and these objects had to adapt to them. The last rule was to break with the "reality of memory", which is also likely in the case of Niaux. The dates obtained show a huge time difference between the creation of paintings and the time in prehistory where traces of its visiting were left.

The situation seems even more obvious when we consider Niaux's site, but also La Vache as a "sites of memory" from a modern point of view. Contemporary perception, approach to these positions is consistent with P. Nora's definition of "sites of memory" for which he considers "is any significant entity, whether material or nonmaterial in nature, which by dint of human wiil or the work of time has become a symbolic element of the memorial heritage of any community" (Nora, 1996a, p. XVII). Certainly they are perceived as an element of cultural heritage, and the approach to these monuments is characterized by the "will to remember". It is certified by research carried out, or care of these monuments. Returning to the determinants of P. Nory, the next was the passage of time and "the ability to change, the potential to create new meanings and content in 
changing social conditions" (Żuk, 2015, s. 82). The passage of time is obvious, also from the point of view of the present day the meaning and content that we read and how we understand these caves is certainly different than it was for their creators. Certainly, there was also a break with the "reality of memory". These places were rediscovered in the 20th century. It is likely, however, that they have been discovered many times. Accompanying paleolithic graffiti paintings in the Niaux cave, they can testify (Minta-Tworzowska, 2018). In this case, the palimpsest character of these places is visible (Frydryczak, 2015; Rybicka, 2015).

The article assumes that the "landscape of memory" is an area where places/signs etc. can be found, which as such will identify it as part of a wider cultural space. In addition, it is a space through which and in which the identity of a given community is visible. In it, there are things that constitute an important symbol / sign or which evoke emotions. The "landscape of memory" is an area with a real, material form, but with an imaginary character, depending on who refers to it. Thus, its meaning and perception is diverse, as it is a social, anthropological, historic, "storage" structure of many cultural memories that give it a palimpsest character (Assmann, 2009; Kapralski, 2010; Frydryczak, 2015; Minta-Tworzowska, 2015a; Rybicka, 2015). The caves of La Vache and Niaux interpreted from the present perspective as a "sites of memory”, considered in a broader spatial and cultural context, constitute important elements of the "landscape of memory" that uniquely identify and give it such a rank. In addition, the relationships between these two positions show that they can, or even should be treated together. In this approach, it is possible to examine them in the context of the "landscape of memory", characterized by palimpsest character, multidimensional, heterogeneous complex of meanings and imaginary character. 